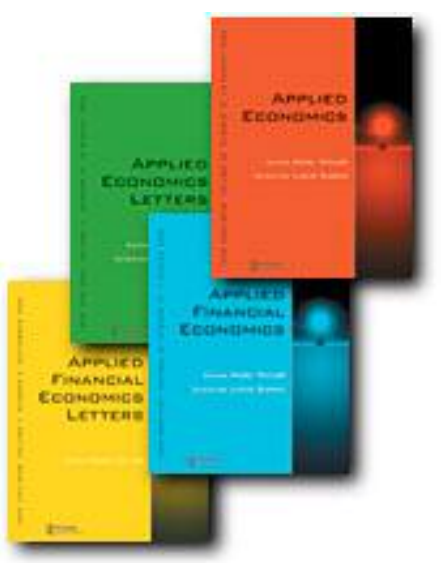

Different ways of looking at old issues: A time series approach to inequality and growth

\begin{tabular}{|r|l|}
\hline Journal: & Applied Economics \\
\hline Manuscript ID: & APE-05-0481.R1 \\
\hline Journal Selection: & Applied Economics \\
\hline JEL Code: & $\begin{array}{l}\text { N10 - General, International, or Comparative < N1 - } \\
\text { Macroeconomics and Monetary Economics|Growth and Fluctuations } \\
\text { L N - Economic History, O15 - Human Resources|Income } \\
\text { Distribution|Migration < O1 - Economic Development < O - } \\
\text { Economic Development, Technological Change, and Growth, O11 - } \\
\text { Macroeconomic Analyses of Economic Development < O1 - } \\
\text { Economic Development < O - Economic Development, } \\
\text { Technological Change, and Growth }\end{array}$ \\
\hline Keywords: & \begin{tabular}{l} 
cointegrated VAR, economic growth, income inequality \\
\hline
\end{tabular} \\
\hline
\end{tabular}

powered by ScholarOne

Manuscript Central ${ }^{\text {TH }}$ 


\title{
Different Ways of Looking at Old Issues: A Time Series Approach to Inequality and Growth
}

\author{
Niko Gobbin* \\ Glenn Rayp \\ Department of Economics \& SHERPPA \\ Ghent University
}

April 2006

\begin{abstract}
In this paper we propose an econometric approach that steers clear of parameter heterogeneity, omitted variable bias and endogeneity problems, from which suffers the econometric analysis of economic growth. We propose to investigate the relation between income inequality and economic growth in a cointegrated VAR-setting and present an application to Belgium, the US and Finland.
\end{abstract}

Keywords: income inequality, economic growth, cointegrated VAR

JEL Classification: E62, N10, O11, O15

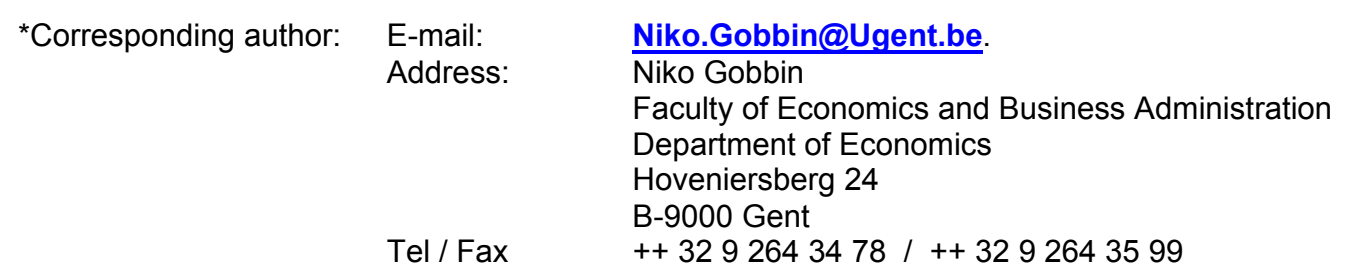

The authors would like to thank Katarina Juselius, Rafael Doménech, David de la Croix, Freddy Heylen, Gerdie Everaert, Jozef Plasmans and two anonymous referees for useful comments and suggestions. We would also like to thank Christian Valenduc, Markus Jäntti and all others that helped with the dataset. Any remaining errors are ours.

We acknowledge support from the Federal Public Planning Service Science Policy, Interuniversity Attraction Poles Program Belgian Science Policy [Contract No. P5/21] 


\section{Introduction}

The question whether and how inequality is related to economic growth inspired a lot of empirical research over the past decade. In the early 1990s, several authors showed that higher inequality at the beginning of a longer-term period was linked to poorer growth performances (Alesina and Rodrik (1994), Perotti (1994, 1996), Persson and Tabellini (1994)). This resulted in a consensus that inequality worsens growth performances. Gradually the consensus weakened. First, it was argued that the relationship differs between poor and rich countries (Deininger and Squire (1998), Barro (1999)). A negative relationship was found in developing countries, but for richer countries there was no relation at all. Second, evidence was found of the opposite relationship: inequality stimulates economic growth (Forbes (2000), Arjona et al. (2001)).

In addition, economic research becomes increasingly sceptical about empirical studies of economic growth. A decade ago, the construction of new, large scale databases raised high expectations in the empirical research of economic growth (e.g., Samuelson, 1997). At present, however, few scholars would disagree with Durlauf (2001) who notes that 'while we have seen remarkable advances in the econometric analysis of many areas of microeconomics and macroeconomics, growth economics has not experienced anything close to such progress' (p. 65).

Durlauf (2001) motivates his statement by the econometric shortcomings of the early empirical work in the study of economic growth. Typical of this approach is the analysis by cross-section OLS regression where growth is regressed on several (lagged) explanatory variables as GDP, schooling, ... and income inequality (Barro and Sala-I-Martin, 1995). This analysis suffers from three major econometric problems : omitted variable bias, functional heterogeneity and endogeneity bias.

The omitted variable bias is especially problematic in growth empirics. On the one hand, the list of factors that can plausibly affect growth seems without limit. On the other hand, the 
number of data points that is available for growth regressions is small. Hence, a lot of potentially relevant regressors need to be excluded. A panel data estimation by fixed effects may reduce the omitted variable problem as the time invariant country specific factors are taken into account (Arjano et al. (2001), Forbes (2000)). However, a new problem arises as estimation by fixed or random effects is not consistent if a lagged endogeneous variable is included in the regression (Nickell (1981)). Growth is known to be characterised by a conditional convergence effect, which renders the fixed and random effects estimators useless for this kind of analysis. An alternative is the use of a first-difference GMM estimator (Forbes (2000)). This estimator eliminates the country specific effects, provided that appropriate instruments are found. If the first stage relationship between the differenced independent variables and lagged level variables is weak, the GMM estimates will be biased towards their fixed-effects counterparts (Stock et al. (2002)). In addition, Blundell et al. (2000) show that the instruments used in the first-difference GMM become less informative with series that are highly autoregressive. As inequality series are characterised by a high degree of persistence, there is a substantial risk that the GMM-results have a large finite sample bias.

Durlauf and Johnson (1995) and Canova (1999) show that the assumption of parameter homogeneity in standard growth analyses is neither supported by the data, nor by theory. Park (1994) notes that although the suggestive empirical results established in the crosscountry analyses can provide a useful guide for country studies, the challenge of empirical work is testing the theoretical insights against the economic evolution of individual countries using time series data. Relevant country specific information gets lost amidst the large number of factors affecting growth performance in cross-country studies. Also Forbes (2000) calls for a within-country reassessment of the linkage between growth and inequality.

Finally, endogeneity is a major problem in growth regressions. A lot of variables have an impact on the growth performance, but growth in turn influences almost all economic 
decisions. Using an instrumental variable approach is not straightforward, as it is problematic to identify instruments that simultaneously are correlated with the included growth determinants and uncorrelated with the residuals. A valid instrument should be uncorrelated with all growth determinants not embodied by the regression. But because so many factors can plausibly influence growth, this condition is virtually impossible to satisfy. Explaining subsequent growth by including explanatory variables at the beginning of the period, does not fully solve the endogeneity problem either, since expectations about economic growth will matter in the decision-making process with respect to schooling, investment, ...

In this paper we explore to what extent we can cope with the above problems by estimating country specific models and by testing for cointegration in a VAR-framework (Johansen and Juselius (1994), Johansen (1995)). While endogeneity and omitted variables still matter, the validity of the results based on the Johansen cointegration analysis depends less on their absence than the validity of results obtained by means of other methodologies.

The country specific, time series approach steers clear of the shortcomings of the usual cross-country approach:

1) By focusing exclusively on the time dimension in the data we avoid heterogeneity problems. However, we have to maintain the assumption of homogeneity over time within a country. Maddala and Wu (2000) find some limited evidence of instability over time in growth relationships.

The individual country approach is in line with Durlauf (2001) who states that: 'Empirical growth studies virtually always assume that one theory is equally valid for all countries, whereas it is far more natural to think a given theory will explain the growth experience of each country more or less well depending on the country's individual characteristics' (p.69).

In addition, we steer clear of data comparability problems across countries. Atkinson and Brandolini (1999) show that, even within the so-called 'high quality' data subset of the Deininger and Squire data, comparability across countries remains problematic. 
2) Given the major endogeneity problems in growth econometrics and the difficulty of finding adequate instruments, a vector autoregressive (VAR) model seems to be the most suitable framework for our analysis. A VAR model does not impose a priori restrictions (with respect to stationarity, causality, ...) on the estimates. One exception is the assumption of a linear relationship between the different variables. This assumption is not undisputed (Banerjee and Duflo (2003)). However, for the countries included in the application, the dispersion of most variables is limited. Given this limited range, the linearity assumption is justified.

While the VAR approach allows us to identify long run (cointegrating) relationships between the variables in the analysis, we cannot make a straightforward statement about the direction of causality. Yet by imposing overidentifying restrictions on the cointegrating vectors we can discriminate between competing models of inequality and growth, which is the essence of the inequality growth debate (Perotti, 1996).

3) The omitted variable problem for growth regressions seems impossible to remedy. However, contrary to previous results, it does not affect the reliability of our estimates. An omitted variable will either be stationary, in which case the estimated coefficients of the cointegrating relationship are invariant to its inclusion, or it will be non-stationary, in which case we will not be able to obtain a stable cointegrating relationship if we leave it out. The cointegration property is invariant to extensions of the information set. If cointegration between a set of variables is detected, the same cointegrating relation will be found in an enlarged variable set (Johansen, 2000). Only if an omitted variable is strongly correlated with one of the variables in the cointegration analysis we can end up with spurious cointegration estimates (see Choi, Hu and Ogaki, 2005) ${ }^{1}$. On that account, we avoid ad hoc choices and only select variables that are supported by the theoretical models.

In the remaining sections of the paper we will illustrate the usefulness of our approach with an application to Belgium, Finland and the US.

\footnotetext{
${ }^{1}$ We thank an anonymous referee for pointing this out to us (and for the useful reference).
} 


\section{Perotti (1996) revisited: a cointegration analysis of inequality and growth}

In the empirical application we use the time series approach to examine the relationship between inequality and growth. We assess the validity of the complete markets model (CMM) and the imperfect markets model (IMM) for Belgium (extensive social insurance), the US (limited social insurance) and Finland (Scandinavian welfare state). Hence, we transpose the cross-section analysis presented in the seminal contribution by Perotti (1996) to a time series framework. In the CMM an economic agent can fully borrow against the present discounted value of future earnings. High inequality affects investment decisions, since more government intervention will be demanded by the population. Redistribution reduces growth through tax distortions and reduced capital accumulation. In the IMM not all planned human capital investment is executed as credit markets malfunction. Redistribution to the poor relaxes the credit constraint thereby stimulating growth. Like Perotti (1996), we proceed by formulating the basic predictions of the two theories of inequality and growth that we consider. Next, we verify whether we can impose restrictions on the cointegrating vectors in the VAR framework that are consistent with the predictions of the CMM or the IMM hypotheses. The derivations of the testable implications of the theories are presented in appendix.

Based on the testable implications, we include income inequality, enrolment in secondary and higher education, economic growth and social security expenditure into the VAR specification. It seems plausible that the evolution of enrolment in secondary education was a driving force for economic growth at the beginning of our sample (the 1960s), but that enrolment in higher education has gradually taken over this leading role. To capture the total effect of enrolment we include both secondary and tertiary education in the estimation. Social security expenditure serves as a proxy for redistribution (see Sinn (1994), Wigger (2001)). Income inequality is measured by means of the gini coefficient. Consistent annual time series for the gini coefficient over a longer period of time are hard to find. We gathered the data 
from local data agencies and income inequality specialists. The scarcity of the inequality time series also implies that the available data do not always allow for a perfect test of the theoretical models (cf. infra). Table 1 gives an overview of the data.

\section{<insert table 1 around here>}

\section{Unit root tests}

In theory inequality measures and enrolment rates cannot be non-stationary: by definition they are bounded and cannot rise or decline forever. However, over the limited time period considered in empirical work they can resemble a unit root process (Parker (2000)). In that case, one should handle them as such (Campbell and Perron (1991)) ${ }^{2}$. To test for the presence of a unit root it is important to use a regression that mimics the actual datagenerating process. If not all deterministic regressors are included, the power of the ADF-test will drop substantially. The power will also be reduced if a regressor is inappropriately added (Enders, 1995). As we do not know the actual data-generating process, we apply the testing procedure proposed by Enders (1995, p. 256-257). By means of the KPSS-test we check the reliability of the results of the ADF-tests that are known to have low power for highly persistent series (Kwiatkowski et al., 1992).

\section{<insert table 2 around here>}

The unit root and stationarity tests do neither allow for a uniform nor for an unambiguous classification. E.g., the tests indicate that while the series of social security expenditure has a unit root in Belgium and the US, the Finnish counterpart seems to be trend stationary. More troublesome (although common in applied work) is that the tests are mutually inconsistent in some cases ${ }^{3}$. Overall, the unit root and stationarity tests indicate that non-stationarity is an additional problem one should take into account when testing for the relationship between

\footnotetext{
2 This comment is equally valid for the analysis of unemployment rates (see e.g., Papell et al. (2000)). We circumvented the problem by testing for the presence of a unit root using logit-transformed data. These constructed variables vary between zero and plus infinity. The conclusions were unchanged.

${ }^{3}$ Income inequality in Belgium (before taxes) and Finland; Enrolment in secondary education in Finland and the US; Enrolment in tertiary education in Belgium and the US.
} 
inequality and growth. Hence, the results motivate our cointegration approach. Following Johansen (2000), we include all variables in the cointegration analysis and perform multivariate stationarity tests to check whether a series can be excluded. Johansen (2000) supports the inclusion of stationary variables in the cointegration analysis since stationarity of an individual variable is just a special case of cointegration in which the cointegrating vector is equal to a unit vector. Since the univariate unit root tests show that some series display trending patterns we will allow for these trends in the analysis. However, Toda (1993) and Gonzalo and Lee (1998) show that Johansen's procedure is potentially flawed by the inclusion of near unit root variables in the VAR. Smallwood and Norrbin (2004) illustrate that the inclusion of trend stationary variables can lead to spurious cointegration and incorrect identification of the cointegrating vectors. The univariate tests indicate that the series for income inequality (before taxes) in Belgium, social security in Finland and enrolment in tertiary education in the US can be identified as trend stationary processes. While we cannot exclude problems of spurious cointegration, we partially deal with them by applying a small sample correction for the determination of the cointegrating rank (cf. infra). Secondly, according to Smallwood an Norrbin (2004) a large difference between the trace and the maximum eigenvalue test might hint at estimation problems due to the presence of trend stationary variables. But there are no large discrepancies between these tests in our analysis ${ }^{4}$.

\section{Cointegration analysis}

From the VAR specification with lag length $k$ results a $1^{\text {st }}$ order vector error correction model (VECM) of the following form:

$$
\Delta X_{t}=\Phi q_{t}+\Pi X_{t-1}+\sum_{i=1}^{k-1} \Gamma_{i} \Delta X_{t-i}+\varepsilon_{t}
$$

\footnotetext{
${ }^{4}$ We report the conclusion concerning the cointegrating rank on the basis of the maximum eigenvalue test $(95 \%$ significance level) in a footnote to table 3
} 
where $X_{t}$ is a $5 \times 1$ vector containing enrolment in secondary and tertiary education, growth, income inequality and social security expenditure in year $t, q_{t}$ holds all deterministic variables and $\varepsilon_{t}$ is de vector of i.i.d. error terms. If not all variables in $X_{t}$ are (trend) stationary, the matrix $\pi$ will not be of full rank. If the system is cointegrated, i.e. there exist linear combinations of the non-stationary variables which are stationary, we can rewrite $\pi$ as the product of two full column rank matrices, $\Pi=\alpha \beta^{\top}$. Both matrices are of dimension $5 \mathrm{xr}$, with $r$ being the number of cointegrating relations.

We initially restrict the trend to the cointegration space and leave the constant unrestricted (see Franses (2001)). Hence, the above expression can be rewritten as:

$$
\Delta X_{t}=\phi_{0}+\alpha \beta^{T} X_{t-1}+\alpha \beta_{2}{ }^{T} t+\sum_{i=1}^{k-1} \Gamma_{i} \Delta X_{t-i}+\varepsilon_{t} .
$$

The matrix $\beta$ contains the long run (cointegrating) relationships, the matrix $\alpha$ the short run adjustments towards these long run equilibria.

As the time dimension of our series is limited, we cannot use asymptotic theory and need to perform small sample corrections (Johanssen (2002a, 2002b)).

\section{Specification tests}

Sumner (2004) highlights the sensitivity of the Johansen cointegration procedure to the choice of the lag length. Bahmani-Oskooee and Brooks (2003) introduce a criterion based on the goodness of fit of the cointegrating vectors to determine the appropriate lag length of the VAR. On the basis of this criterion we decide to include two lags in the VAR specification of Finland and Belgium with inequality after taxes, and three lags in that of the US and Belgium with inequality before taxes ${ }^{5}$.

To evaluate the appropriateness of the lag length we also test for autocorrelation in the error terms. Based on its superior behaviour in small samples we apply the F-approximation of the

\footnotetext{
${ }^{5}$ Based on the Akaike Information Criterion we would choose 2 lags for Belgium and 3 lags for Finland. The qualitative results of the cointegrating analysis are fairly robust to these changes.
} 
Lagrange-multiplier vector error autocorrelation test (Doornik (1996)). The results indicate that autocorrelation of the error terms is not a problem.

A likelihood ratio test shows that we can remove the trend from the cointegration space for Belgium but not for Finland and the US ${ }^{6}$.

\section{The cointegrating rank}

For the determination of the cointegrating rank we evaluate the trace statistic against its $95 \%$ asymptotic critical value. Johansen (2002a) illustrates that the actual probability of rejecting a correct null hypothesis in a finite sample is much larger than the $5 \%$ nominal value. He introduces a correction factor for the trace statistic to deal with this size distortion. Österholm (2004) shows that this procedure has a more robust performance than some alternative corrections. If we reject the null hypothesis with the asymptotic critical values, we also look at the corrected ones. In the table the corrected values are in italic. We also report the asymptotic values in brackets if the conclusion about the rank changes because of the correction.

\section{<insert table 3 around here>}

For Belgium with income after taxes, Finland and the US we do not reject the hypothesis of "two cointegrating vectors". If we would not apply the small sample correction, we would only reject the alternative hypothesis of "more than two cointegrating vectors" at levels of significance above $97,5 \%$.

For Belgium with income before taxes we marginally reject "more than one cointegrating vector" on the basis of the corrected asymptotic values at the $95 \%$ significance level. But we do not reject this hypothesis if we look at the $90 \%$ level. An identical picture emerges if we consider the maximum eigenvalue test.

\footnotetext{
${ }^{6}$ Belgium with inequality before taxes: $\chi_{(2)}^{2}=3,306(p: 0,192)$; Belgium with inequality after taxes: $\chi_{(2)}^{2}=2,941$ (p-value: 0,230$)$; US: $\chi_{(2)}^{2}=7,913$ ( $p$-value : 0,019); Finland: $\chi_{(2)}^{2}=16,619$ ( $p$-value : 0,000 )
} 
In the remaining part of the analysis we will assume that the assumption of "two cointegrating vectors" is appropriate in all cases.

\section{Identification of the long term relationships}

Firstly, we perform some multivariate stationarity tests. The likely (trend)stationarity of economic growth (cf. table 2) is not confirmed by these multivariate tests. Stationarity is also rejected for the other variables. Hence, we maintain all variables in the cointegration analysis.

Secondly, we check whether we can identify a cointegrating vector in which there is a direct relationship between income inequality and economic growth. However, we can never reduce the cointegrating vector to just these two variables.

Thirdly, we try to identify the cointegrating vectors in terms of the models of income inequality and economic growth. In the presence of multiple cointegrating relations, the estimates are not unique and directly interpretable. We can identify the long term relationships between the variables by imposing coefficient restrictions on the long term relations $(\beta)$ and the short run adjustments $(\alpha)$. The choice of restrictions is based on the testable results of the IMM and CMM (see appendix). The number of model implications we can test simultaneously is equal to the number of cointegrating relationships. Again, Johansen (2002b) notes that the asymptotic results of the estimates are not accurate enough for small samples. His results indicate that the actual size can be quite distorted (much larger than the nominal size) in small samples. To convincingly reject the restrictions, the p-value should be sufficiently below $5 \%$.

By imposing identification restrictions on the cointegrating vectors, we verify whether the cointegrating vectors are consistent with respectively the testable implications of IMM and the CMM: 
IMM growth relation:

IMM1: Growth increases as enrolment increases (controlled for social security);

IMM2: Growth decreases as social security increases (controlled for enrolment). IMM enrolment relation:

IMM3: Enrolment increases as inequality decreases (controlled for social security);

IMM4: Enrolment increases as social security increases (controlled for inequality). CMM growth relation:

CMM1: Growth decreases as social security increases.

CMM social security relation:

CMM2: Social security increases as inequality increases.

We check with log-likelihood ratio tests whether IMM1-IMM4 or CMM1-CMM2 can be rejected.

However, the identification of multiple cointegrating vectors is not unique and changing the order in which restrictions are imposed can change the results. Therefore, we systematically explore the different sequences of restrictions. If we find both a growth and enrolment relation compatible with IMM1-IMM4 in the first step, we can argue that the data do not reject the IMM. Next we check whether the implications of the CMM are compatible with the long run relations. In table 4 we present the identified cointegrating relations.

\section{<insert table 4 around here>}

For Belgium we find that enrolment is negatively influenced by inequality before taxes. However, the coefficient is not statistically significant and we can remove inequality from the cointegrating relation. Social security expenditure has a significant positive impact on enrolment. In the IMM redistribution matters for enrolment because it reduces (postredistribution-)inequality. Therefore, we might not detect the positive effect of redistribution 
on enrolment if the tax system is highly redistributive ${ }^{7}$ and we include after-tax-inequality in the estimation. Our estimates for income after taxes confirm this conjecture. We cannot remove inequality after taxes from the enrolment relation. This results seem to imply that the tax system in Belgium, while having redistributive effects, does not fully eliminate credit constraints.

Social security is negatively related to growth, which is compatible with both the IMM and the CMM. Enrolment in secondary education is positively related to growth. The impact of enrolment in higher education on growth is not significant. We cannot identify a social security relation in line with the CMM. Overall, the data for Belgium seem to be more in line with the implications of the IMM.

For the US we find that social security expenditure is positively related to income inequality, but the coefficient is only marginally significant. Enrolment in tertiary education has a strong negative impact on social security expenditure. Economic growth is positively affected by enrolment in higher education and by income inequality. The US growth relation resembles the one identified by Forbes (2000) for a panel of countries: controlled for enrolment, economic growth is positively affected by income inequality. Just as Forbes we observe a dubious impact of education. Enrolment in secondary education has a positive impact on growth, while the impact of enrolment in higher education is negative (and smaller in absolute terms). In Forbes' results the impact of education differs depending on the gender. Social security expenditure does not have a negative impact on the growth rate. But we can neither identify a positive impact of redistribution on enrolment for the US. Hence, overall the US data seem to offer some partial support for the CMM.

For Finland we fail to identify the cointegrating vectors in terms of either the IMM or the CMM. As there exist many other theories that account for the relationship between inequality

\footnotetext{
${ }^{7}$ According to Van den Noord and Heady (2001) the tax system in Belgium is highly progressive while the tax system in the US has only limited redistributive effects.
} 
and growth (e.g., Viaene and Zilcha, 2001), this is not a surprising finding. However, it underlines the usefulness of our country-specific approach. Next to the flexibility this approach offers in terms of the empirical specification (e.g., the inclusion of a trend in the cointegrating relation for the US and Finland, but not for Belgium), it also allows for model heterogeneity between countries.

\section{Conclusions}

Durlauf (2001) urged growth economists to advance in the field of growth econometrics. We propose a methodology that deviates in two ways from existing work: firstly, we use a time series approach instead of a cross section or panel analysis, and secondly, we resort to the Johansen cointegration framework, a methodology that, to our knowledge, has not been applied before in growth econometrics. These innovations steer clear of heterogeneity, omitted variables and endogeneity problems. We applied the methodology to the analysis of the relation between income inequality and economic growth in Belgium, the US and Finland. The results for Belgium offer support for the IMM, while the US data seem more in line with the CMM and confirm the results of Forbes (1990). The Finnish data do neither fit the IMM nor the CMM. The heterogeneity of our results matches the mixed results of previous cross section and panel studies. Thus, the different results of these studies are not solely caused by methodological differences but also reflect the fact that different inequality-growth models hold for different countries. A country specific estimation approach is needed since one-sizefits-all' does not apply in the field of growth empirics. 


\section{References}

Aghion P., Howitt P. (1998): Endogenous Growth Theory, MIT Press, Cambridge

Alesina A., Rodrik D. (1994): Distributive Politics and Economic Growth, Quarterly Journal of Economics, 109, p.465-490

Arjona R., Ladaique M., Pearson M. (2001): Growth, Inequality and Social Protection, OECD Labour Market and Social Policy Occasional Papers no. 51, 80p.

Atkinson A., Brandolini A. (1999) : Promise and Pitfalls in the Use of "Secondary" Datasets: Income Inequality in OECD countries, mimeo, 60p.

Bahmani-Oskooee M., Brooks T. J. (2003): A New Criteria for Selecting the Optimum Lags in Johansen's Cointegration Technique, Applied Economics, 35, p.875-880

Banerjee A. V., Duflo E. (2003): Inequality and Growth: What Can the Data Say?, Journal of Economic Growth, 8, p.267-299

Barro R. J., Sala-I-Martin X. (1995): Economic Growth, McGraw-Hill, New York

Barro R. J. (1999): Inequality, Growth and Investment, NBER Working Paper no. 7038, 37p.

Bénabou R. (1996): Inequality and Growth, in: Bernanke B.S. and Rotemberg. J. (eds.), NBER Macroeconomics Annual 11, MIT Press, p.11-92

Bils M. and Klenow P. J. (2000): Does Schooling Cause Growth, The American Economic Review, vol. 90 (5), p.1160-1183

Blundell Ri., Bond S., Windmeijer F. (2000): Estimation in Dynamic Panel Data Models: Improving on the Performance of the Standard GMM Estimator, IFS Working Paper no. $00 / 12,46 p$.

Campbell J.Y., Perron P. (1991): Pitfalls and Opportunities: What Macroeconomists Should Know about Unit Roots, NBER Technical Working Paper no. 100, 67p.

Canova F. (1999): Testing for Convergence Clubs in Income per Capita: A Predictive Density Approach, CEPR Discussion Paper no. 2201, 28p.

Choi C.-Y., Hu L. and Ogaki M. (2005): Structural Spurious Regression and A Hausman-type Cointegration Test, RCER Working Paper No. 517, 38p.

Davis S. J., Henrekson M. (2004) : Tax Effects on Work Activity, Industry Mix and Shadow Economy Size: Evidence from Rich-Country Comparisons, NBER Working Paper no. 10509, $64 p$.

Deininger K., Squire L. (1998): New Ways of Looking at Old Issues: Inequality and Growth, Journal of Development Economics, 57, p.259-287

Doornik J.A. (1996): Testing Vector Autocorrelation and Heteroscedasticity in Dynamic Models, URL: www.nuff.ox.ac.uk/users/doornik, Nuffield College

Durlauf S. N., Johnson P. (1995): Multiple regimes and cross-country growth behavior, Journal of Applied Econometrics, 10, p.365-384 
Durlauf S. N. (2001): Manifesto for a Growth Econometrics, Journal of Econometrics, 100, p.65-69

Enders W. (1995): Applied Econometric Time Series, Wiley Series in Probability and Mathematical Statistics, John Wiley and Sons Inc., New York

Forbes K. J. (2000): A Reassessment of the Relationship Between Inequality and Growth, The American Economic Review, 90 (4), p.869-887

Franses P. H. (2001): How to Deal with Intercept and Trend in Practical Cointegration Analysis?, Applied Economics, 33, p.577-579

Gonzalo J., Lee T.-H. (1998): Pitfalls in testing for long run relationships, Journal of Econometrics, 86, p.129-154

Johansen S., Juselius K. (1994): Identification of the long-run and the short-run Structure. An Application to the ISLM Model, Journal of Econometrics, 63, p.7-36

Johansen S. (1995): Likelihood-Based Inference in Cointegrated Vector Autoregressive Models', Advanced Text in Econometrics, Oxford University Press, Oxford

Johansen S. (2000): Modelling of Cointegration in a Vector Autoregressive Model, Economic Modelling, 17, p.359-373

Johansen S. (2002a): A Small Sample Correction for Tests of Cointegrating Rank in the Vector Autoregressive Model, Econometrica, 70 (5), p.1929-1961

Johansen S. (2002b): A Small Sample Correction for Tests of Hypotheses on the Cointegrating Vectors, Journal of Econometrics, 111, p.195-221

Kwiatkowski D., Phillips P., Schmidt P., Shin Y. (1992): Testing the null hypothesis of stationarity against the alternative of a unit root, Journal of Econometrics, 54, p. 159-178

Lindbeck A. (1985): What is Wrong with the West European Economies, World Economy, 8 (2), p.153-169

Lindbeck A. (1988): Consequences of the Advanced Welfare State, World Economy, 11 (1), p.19-37

Lindbeck A. (1993): Work Disincentives in the Welfare State, in: Lindbeck A., The Welfare State - The Selected Essays of Assar Lindbeck Vol. II, Edward Elgar, Hants

Maddala G.S., Wu S. (2000): Cross-country Growth Regressions: Problems of Heterogeneity, Stability and Interpretation, Applied Economics, 32, p.635-642

Meltzer A. H., Richard S. F. (1981): A Rational Theory of the Size of Government, Journal of Political Economy, 89 (5), p.914-927

Nickell S. J. (1981): Biases in Dynamic Models with Fixed Effects, Econometrica, 49 (6), p.1417-1426

OECD (2002): Statistical Compendium on CD-Rom 2002/1. 
Österholm P. (2004): Size Properties of Cointegration Tests in Misspecified Systems, Applied Economics Letters, 11 (15), p.919-924

Papell D.H., Murray C.J., Ghiblawi H. (2000): The Structure of Unemployment, The Review of Economics and Statistics, 82 (2), p.309-315

Park H. (1994): Endogenous Growth Theory: Intellectual Appeal and Empirical Shortcomings, Journal of Economic Perspectives, 8 (1), p.55-72

Parker S. C. (2000): Opening a can of worms: the pitfalls of time-series regression analyses of income inequality, Applied Economics, 32, p.221-230

Perotti R. (1994): Income Distribution and Investment, European Economic Review, 38, p.827-835

Perotti R. (1996): Growth, Income Distribution and Democracy: What the Data Say, Journal of Economic Growth, 1 (2), p.149-187

Persson T., Tabellini G. (1994): Is Inequality Harmful for Growth, The American Economic Review, 84 (3), p.600-621

Psacharopoulos G. (1994): Returns to Investment in Education: A Global Update, World Development, 22 (9), p.1325-1343

Sinn H.-W. (1994): A Theory of the Welfare State, NBER Working Paper No. 4856, 38p.

Samuelson P. A (1997): Growth Theory Tries Once Again, Japan and the World Economy, 9 (2), p. $283-86$

Smallwood A.D., Norrbin S.C. (2004): Estimating cointegrating vectors using near unit root variables, Applied Economic Letters, 11, p.781-784

Stock J., Wright J., Yogo M. (2002): A Survey of Weak Instruments and Weak Identification in GMM, Journal of Business and Economics Statistics, 20 (4), p.518-529

Sumner M. (2004): A cautionary note on cointegration testing, Applied Economics Letters, 11, p.275-278

Van den Noord P., Heady C. (2001): Surveillance of Tax Policies: a Synthesis of Findings in Economic Surveys, OECD Economic Department Working Papers, no. 303, 85p.

Viaene J.-M., Zilcha I. (2001): Human Capital Formation, Income Inequality and Growth, CESifo Working Paper no. 512, 30p.

Wigger B. U. (2001): Gifs, Bequests, and Growth, Journal of Macroeconomics, 23 (1), p.121129 
Table 1: Data description

\begin{tabular}{|c|c|c|c|}
\hline Series & Series' description & Data Source & Period \\
\hline $\begin{array}{l}\text { Enrolment rate - } \\
\text { Belgium }\end{array}$ & $\begin{array}{l}\text { Secondary education / } \\
\text { Population aged 12-17 } \\
\text { Tertiary education / Population aged 18- } \\
22\end{array}$ & $\begin{array}{l}\text { NIS - Statistical Yearbook } \\
\text { NIS - Population Statistics } \\
\text { NIS - Statistical Yearbook } \\
\text { NIS - Population Statistics }\end{array}$ & $\begin{array}{l}1960-2000 \\
1960-2000 \\
1960-2000 \\
1960-2000\end{array}$ \\
\hline $\begin{array}{l}\text { Enrolment rate - } \\
\text { US }\end{array}$ & $\begin{array}{l}\text { High School students / } \\
\text { Population aged } 12-17 \\
\text { College students / } \\
\text { Population aged } 18-22\end{array}$ & $\begin{array}{l}\text { US Census Bureau } \\
\text { US Census Bureau } \\
\text { US Census Bureau } \\
\text { US Census Bureau }\end{array}$ & $\begin{array}{l}1960-2000 \\
1960-2000 \\
1960-2000 \\
1960-2000\end{array}$ \\
\hline $\begin{array}{l}\text { Enrolment rate - } \\
\text { Finland }\end{array}$ & $\begin{array}{l}\text { Secondary education / } \\
\text { Population aged 13-18 } \\
\text { Tertiary education / } \\
\text { Population aged 19-23 }\end{array}$ & $\begin{array}{l}\text { Mitchell (1998) } \\
\text { Statistics Finland } \\
\text { SF - Statistical Yearbook } \\
\text { Statistics Finland }\end{array}$ & $\begin{array}{l}1960-1993 \\
1960-2001 \\
1960-1993 \\
1960-2001\end{array}$ \\
\hline Economic growth & $\begin{array}{l}\text { Changes in the log of GDP at market } \\
\text { prices, in volume and at local currency }\end{array}$ & OECD Economic Outlook & $1960-2000$ \\
\hline $\begin{array}{l}\text { Social security } \\
\text { expenditure }\end{array}$ & $\begin{array}{l}\text { Public and mandatory private social } \\
\text { security expenditure as a } \% \text { of GDP }\end{array}$ & $\begin{array}{l}\text { OECD Social Expenditure } \\
\text { Database / ILO }\end{array}$ & $1960-2000$ \\
\hline $\begin{array}{l}\text { Income inequality } \\
\text { - Belgium }\end{array}$ & $\begin{array}{l}\text { Gini coefficient of income before taxes } \\
\text { Gini coefficient of income after taxes }\end{array}$ & $\begin{array}{l}\text { Valenduc (Tax data) } \\
\text { Valenduc (Tax data) }\end{array}$ & $\begin{array}{l}1965-1998 \\
1965-1998\end{array}$ \\
\hline $\begin{array}{l}\text { Income inequality } \\
\text { - US }\end{array}$ & Disposable household income & US Census Bureau & $1960-2000$ \\
\hline $\begin{array}{l}\text { Income inequality } \\
\text { - Finland }\end{array}$ & Disposable income & Erikson \& Jäntti (Tax data) & $1960-1992$ \\
\hline
\end{tabular}


Table 2: Unit root tests

\begin{tabular}{|c|c|c|c|}
\hline Data series & $A D F$ & KPSS (level stationary) & KPSS (trend stationary) \\
\hline \multicolumn{4}{|l|}{ Income inequality } \\
\hline Belgium (after taxes) & -0.990 & $0.536^{* *}$ & $0.138^{*}$ \\
\hline Belgium (before taxes) & -0.566 & $0.499^{* *}$ & 0.109 \\
\hline US & -0.716 & $0.802^{* * *}$ & $0.216^{* * *}$ \\
\hline Finland & $-2.700^{* *}$ & $0.629^{* *}$ & $0.163^{* *}$ \\
\hline \multicolumn{4}{|l|}{ Economic growth } \\
\hline Belgium & $-5.746^{* * *}$ & $0.822^{* * *}$ & 0.085 \\
\hline US & $-4.910^{* * *}$ & 0.106 & 0.087 \\
\hline Finland & $-3.444^{* *}$ & 0.184 & 0.069 \\
\hline \multicolumn{4}{|l|}{ Social security } \\
\hline Belgium & -1.395 & $1.815^{* * *}$ & $0.391^{* * *}$ \\
\hline US & -1.194 & $1.684^{* * *}$ & $0.363^{* * *}$ \\
\hline Finland & $-4.230^{* * *}$ & $1.268^{* * *}$ & $0.141^{*}$ \\
\hline \multicolumn{4}{|l|}{ Enrolment secondary } \\
\hline Belgium & -1.271 & $2.097^{* * *}$ & $0.224^{* * *}$ \\
\hline US & $-4.668^{* * *}$ & $1.750^{* * *}$ & $0.247^{* * *}$ \\
\hline Finland & $-3.074^{* *}$ & $1.062^{* * *}$ & $0.235^{* * *}$ \\
\hline \multicolumn{4}{|l|}{ Enrolment tertiary } \\
\hline Belgium & $-3.594^{* *}$ & $2.041^{* * *}$ & $0.415^{* * *}$ \\
\hline US & -1.381 & $2.053^{* * *}$ & 0.094 \\
\hline Finland & -1.588 & $1.181^{* * *}$ & $0.198^{* * *}$ \\
\hline
\end{tabular}

Notes: $\quad$ Augmented Dickey Fuller test (ADF): null hypothesis is unit root. The optimal lag length for the test was determined using the Schwarz Bayesian information criterion.

Kwiatkowski Phillips Schmidt Sin Test (KPSS): null hypothesis is (trend) stationarity.

${ }^{*} /{ }^{* *} /{ }^{* * *}$ denotes rejection of null hypothesis at $10 \% / 5 \% / 1 \%$ level 
Table 3: cointegrating rank (growth, social security, income inequality, secondary and tertiary education)

\begin{tabular}{l|l|l|l|l|} 
Country & Rank & Trace & $\begin{array}{l}\text { Trace 95\% - } \\
\text { Corrected values }\end{array}$ & Conclusion \\
\hline \hline Belgium & $\mathrm{H}_{0}: r=0 ; \mathrm{H}_{1}: r>0$ & 100.90 & 82.42 & 2 cointegrating relations is not \\
Income after taxes & $\mathrm{H}_{0}: r \leq 1 ; \mathrm{H}_{1}: r>1$ & 62.66 & 56.65 & rejected \\
(2 lags, no trend) & $\mathrm{H}_{0}: r \leq 2 ; \mathrm{H}_{1}: r>2$ & 33.90 & $35.26(29.38)$ & (asymptotic critical values: 3$)$ \\
\hline Belgium & $\mathrm{H}_{0}: r=0 ; \mathrm{H}_{1}: r>0$ & 80.57 & 75.14 & 1 cointegrating relation is not \\
Income before taxes & $\mathrm{H}_{0}: r \leq 1 ; \mathrm{H}_{1}: r>1$ & 48.21 & $49.23(47.21)$ & rejected \\
(3 lags, no trend) & $\mathrm{H}_{0}: r \leq 2 ; \mathrm{H}_{1}: r>2$ & 21.82 & 34.42 & (asymptotic critical values: 2$)$ \\
\hline US & $\mathrm{H}_{0}: r=0 ; \mathrm{H}_{1}: r>0$ & 137.44 & 92.45 & 2 cointegrating relations is not \\
(3 lags, with trend) & $\mathrm{H}_{0}: r \leq 1 ; \mathrm{H}_{1}: r>1$ & 86.65 & 67.58 & rejected \\
& $\mathrm{H}_{0}: r \leq 2 ; \mathrm{H}_{1}: r>2$ & 57.26 & $64.23(42.20)$ & (asymptotic critical values: 3) \\
\hline Finland & $\mathrm{H}_{0}: r=0 ; \mathrm{H}_{1}: r>0$ & 129.31 & 92.56 & 2 cointegrating relations is not \\
(2 lags, with trend) & $\mathrm{H}_{0}: r \leq 1 ; \mathrm{H}_{1}: r>1$ & 81.33 & 70.21 & rejected \\
& $\mathrm{H}_{0}: r \leq 2 ; \mathrm{H}_{1}: r>2$ & 45.70 & $62.57(42.20)$ & (asymptotic critical values: 3) \\
\hline
\end{tabular}

Note: The figures in italic in the fourth column are corrected values (small samples). If we do not reject the null hypothesis $\left(\mathrm{H}_{0}\right)$ on the basis of the asymptotic value for the trace statistic, we give the asymptotic value (not in italic) as the corrected one can only be higher. If the use of the corrected values changes the conclusion, we also report the asymptotic value (between brackets).

Rank based on maximum eigenvalue test (without finite sample correction): Belgium income after taxes: 2, Belgium income before taxes: 1, Finland: 3 , US: 3.

Table 4: The long term relations

\begin{tabular}{|c|c|c|c|c|c|}
\hline & Growth & Gini & $\begin{array}{l}\text { Secondary } \\
\text { education }\end{array}$ & $\begin{array}{c}\text { Higher } \\
\text { education }\end{array}$ & $\begin{array}{l}\text { Social } \\
\text { security }\end{array}$ \\
\hline $\begin{array}{l}\text { Belgium before taxes } \\
\text { Enrolment relation } \\
\text { Growth relation }\end{array}$ & $\begin{array}{c}0.000 \\
(2.573) \\
1.000\end{array}$ & $\begin{array}{c}0.295 \\
(0.532) \\
0.000\end{array}$ & $\begin{array}{l}1.000 \\
-0.148 \\
(0.044)\end{array}$ & $\begin{array}{c}0.000 \\
(0.489) \\
0.000\end{array}$ & $\begin{array}{c}-0.012 \\
(0.003) \\
0.0051 \\
(0.0001)\end{array}$ \\
\hline $\begin{array}{l}\text { Belgium after taxes } \\
\text { Enrolment relation } \\
\text { Growth relation }\end{array}$ & $\begin{array}{c}-6.926 \\
(0.978) \\
1.000\end{array}$ & $\begin{array}{c}2.549 \\
(0.471) \\
0.000\end{array}$ & $\begin{array}{l}1.000 \\
-0.405 \\
(0.126) \\
\end{array}$ & $\begin{array}{c}-1.592 \\
(0.168) \\
0.000\end{array}$ & $\begin{array}{c}0.000 \\
0.0064 \\
(0.0027) \\
\end{array}$ \\
\hline $\begin{array}{l}\text { US } \\
\text { Social security relation } \\
\text { Growth relation }\end{array}$ & $\begin{array}{l}0.000 \\
1.000\end{array}$ & $\begin{array}{l}-61.645 \\
(32.117) \\
-6.994 \\
(0.894)\end{array}$ & $\begin{array}{l}0.000 \\
-7.666 \\
(0.984)\end{array}$ & $\begin{array}{c}147.900 \\
(22.404) \\
2.729 \\
(0.298)\end{array}$ & $\begin{array}{l}1.000 \\
0.000\end{array}$ \\
\hline
\end{tabular}

Note: $\quad$ Standard errors are reported in brackets.

Coefficient of trend (US) in social security relation: -1.517 ; the trend can be removed from the US growth relation. Finland is not included in the table since the cointegrating vectors could not be identified in terms of the IMM / CMM model implications. 


\section{Appendix: Theoretical fundaments of the estimations}

We formulate the testable implications of both theories from the basic theoretical model of Bénabou (1996) and Aghion and Howitt (1998).

Consider an overlapping generations model in which $n$ individuals live for two periods. The intertemporal utility of an individual $i$ born at time $t$ is given by:

$$
U_{t}^{i}=\ln c_{t}^{i}+\rho \ln d_{t}^{i} \quad 0<\rho<1
$$

where $c$ and $d$ denote current and future consumption respectively. The parameter $\rho$ is a measure of time preference.

The future consumption good is produced according to

$$
y_{t}^{i}=\eta k_{t}^{i}
$$

where the parameter $\eta$ is an efficiency measure, that is a decreasing function of the tax rate $\beta$ (e.g., Lindbeck (1985, 1988 and 1993) and Davis and Henrekson (2004)):

$$
\eta=(1-\kappa \beta) \eta^{*}
$$

with $\eta^{*}$ the maximum efficiency (with zero tax rate) and $0<\kappa \leq 1$.

The term $k_{t}^{i}$ represents the 'society adjusted individual education level:'

$$
k_{t}^{i}=\left(e_{t}^{i}\right)^{\delta}\left(A_{t}\right)^{1-\alpha}, \quad \text { with } 0<\alpha<1,
$$

where $e^{i}$ denotes the education level attained by an individual $i$ and $A$ is the basic level of knowledge and skills in the society. To increase his education level, an individual can invest in human capital $\left(h^{i}\right)$, characterised by decreasing returns (e.g., Psacharopoulos, 1994 and Bils and Klenow, 2000):

$$
e_{t}^{i}=\left(h_{t}^{i}\right)^{\gamma}, \quad \text { with } 0<\gamma=\frac{\alpha}{\delta}<1
$$

The accumulation of knowledge and skills follows from past production activities (learning-bydoing)

$$
A_{t}=\frac{1}{n} \sum_{i} y_{t-1}^{i}
$$


An individual's endowment upon birth at time $t$ is given by $\varepsilon_{t}^{i} A_{t}$, with $\varepsilon^{i}(\geq 0)$ an identically and independently distributed random shock with mean 1 that measures individual $i$ 's access to general knowledge at time of birth and that he can immediately consume or invest in the production of the future consumption good.

In the complete markets model (CMM), current consumption will be equal to the amount of initial endowments augmented with the amount of borrowing $\left(b^{i}\right)$, less the amount of investment in human capital:

$$
c_{t}^{i}=w_{t}^{i}+b_{t}^{i}-h_{t}^{i}
$$

The government redistributes income (intra-generational transfers)by taking away a fraction $\beta$ of individual income and adding a fraction $\beta$ of the average income in the society $(\bar{y})$ to it. Redistribution will have an indirect cost due to its negative impact on efficiency.

Future consumption equals future production after redistribution, less the debt repayment:

$$
d_{t}^{i}=(1-\beta) y_{t}^{i}+\beta \bar{y}_{t}-r_{t} b_{t}^{i}
$$

with $r(>1)$ the (gross) market interest rate endogenously determined by the loan market clearing condition: the sum of net-borrowings must equal 0 ,

$$
\sum_{i} b_{t}^{i}=0
$$

After substitution of (7) and (8) into (1), (10)an individual's decision becomes:

$$
\underset{b_{t}^{i}, h_{t}^{i}}{\operatorname{aax}}\left\{\ln \left(w_{t}^{i}+b_{t}^{i}-h_{t}^{i}\right)+\rho \ln \left((1-\beta) y_{t}^{i}+\beta \bar{y}_{t}-r_{t} b_{t}^{i}\right)\right\} \quad \text { s.t. expression (9). }
$$

Some manipulation of the first order conditions, leads to the following expression for an individual's investment:

$$
h_{t}=h_{t}^{i}=\frac{\rho \alpha(1-\beta)}{1+\rho \alpha(1-\beta)} A_{t} .
$$


Every agent will invest the same amount of capital in the production process (irrespective of his initial endowment). The first derivative with respect to $\beta$ is negative, so redistribution reduces investment levels:

$$
\frac{\delta h_{t}}{\delta \beta}=\frac{-\rho \alpha}{(1+\rho \alpha(1-\beta))^{2}} A_{t}+\frac{\rho \alpha(1-\beta)}{1+\rho \alpha(1-\beta)}\left(-\frac{\kappa}{n} \sum_{i} k_{t-1}^{i}\right)<0
$$

Next we derive an expression for the steady state growth:

$$
g_{y}=\ln \left(\frac{\sum_{i} y_{t}^{i}}{\sum_{i} y_{t-1}^{i}}\right)=\ln \eta^{*}+\ln (1-\kappa \beta)+\alpha \ln \rho \alpha+\alpha \ln (1-\beta)-\alpha \ln (1+\rho \alpha(1-\beta)) \text {. }
$$

The partial derivative of $g$ with respect to $\beta$ is

$$
\frac{\delta g_{y}}{\delta \beta}=-\frac{\alpha}{1-\beta}-\frac{\kappa}{1-\kappa \beta}+\frac{\rho \alpha^{2}}{1+\rho \alpha(1-\beta)}<0 .
$$

Meltzer and Richard (1981) (see also Bénabou (1996)) have shown that the preferred tax rate by the median voter will depend on the relative position of his income to the mean of the income distribution. The larger the gap between the median and the mean income is (i.e. the more skewed to the left the income distribution is), the higher the preferred tax rate will be.

From the results of Meltzer and Richard (1981) and (14) we derive the testable implications of the CMM:

CMM1: Growth decreases as social security increases

CMM2: Social security increases as inequality increases

Now, assume an imperfect market model (IMM) where capital markets are absent ( $b^{i}$ is equal to 0 for all individuals) and the government chooses to redistribute income across generations (intergenerational transfers). 
Current consumption is represented by:

$$
c_{t}^{i}=w_{t}^{i}-h_{t}^{i}+\beta A_{t} .
$$

Each individual receives an equal share of the tax revenues collected from the previous generation:

$$
\frac{1}{n} \sum_{i} \beta y_{t-1}^{i}=\beta A_{t}
$$

Future consumption equals production minus taxes,

$$
d_{t}^{i}=y_{t}^{i}(1-\beta) .
$$

The individual's maximization problem becomes (substitution of (16) and (17) into(1)):

$$
\underset{h_{t}^{i}}{\operatorname{Max}}\left\{\ln \left(w_{t}^{i}-h_{t}^{i}+\beta A_{t}\right)+\rho \ln \left(y_{t}^{i}(1-\beta)\right)\right\}
$$

which leads to

$$
h_{t}^{i}=\frac{\rho \alpha}{1+\rho \alpha}\left(\varepsilon_{t}^{i} A_{t}+\beta A_{t}\right)=\frac{\rho \alpha}{1+\rho \alpha}\left(\frac{\eta^{*}}{n} \sum_{i} k_{t-1}^{i}\right)(1-\kappa \beta)\left(\varepsilon_{t}^{i}+\beta\right) .
$$

In contrast to the perfect markets case, investment will differ across individuals. The first derivative of this expression with respect to redistribution is equal to

$$
\begin{aligned}
& \qquad \frac{\delta h_{t}^{i}}{\delta \beta}=\frac{\rho \alpha}{1+\rho \alpha}\left(\frac{\eta^{*}}{n} \sum_{i} k_{t-1}^{i}\right)\left(-\kappa \varepsilon_{t}^{i}+1-2 \kappa \beta\right) . \\
& \text { The sign of expression (20) will be } \begin{array}{rrr}
>0 & \text { if } \varepsilon_{t}^{i}<\frac{1-2 \kappa \beta}{\kappa} \\
& <0 \text { if } \varepsilon_{t}^{i}>\frac{1-2 \kappa \beta}{\kappa}
\end{array} .
\end{aligned}
$$

As redistribution relaxes credit constraints, the poorly endowed $\left(\varepsilon{ }^{i}\right.$ sufficiently low) will invest more. The 'rich' will invest less. The higher $\kappa$, the higher the 'cost' of the tax system in terms and the lower the number of people that will benefit from redistribution. Substituting (19) into (5) and taking the sum over all individuals, total education can be expressed as:

$$
e_{t}^{t o t}=\left(\frac{\rho \alpha}{1+\rho \alpha}\right)^{\gamma}\left(A_{t}\right)^{\gamma} \sum_{i}\left(\varepsilon_{t}^{i}+\beta\right)^{\gamma}
$$


The effect of redistribution is double: a higher $\beta$ negatively influences efficiency (and thereby the accumulated knowledge and skills, $A$ ) but at the same time leads to in increase of the third factor of expression (21). For normal parameter values the total effect of redistribution will be positive. By Jensen's inequality, a more unequal distribution of endowments (larger variance of $\varepsilon_{t}^{i}$ ), for a given amount of redistribution (fixed $\beta$ ), tends to lower total education.

We can again derive an expression for growth:

$$
g_{y}=\ln \eta^{*}+\ln (1-\kappa \beta)-\ln n+\alpha \ln \left(\frac{\rho \alpha}{1+\rho \alpha}\right)+\ln \left(\sum_{i}\left(\varepsilon_{t}^{i}+\beta\right)^{\alpha}\right) .
$$

In contrast to the CMM, the effect of redistribution on growth is ambiguous. On the one hand, a negative effect is still present through the second term of expression (22). But now there is also a positive impact through the fourth term.

From (21) and (22) we derive the testable implications of the IMM:

IMM1: Growth increases as enrolment increases (controlled for social security).

IMM2: Growth decreases as social security increases (controlled for enrolment).

IMM3: Enrolment increases as inequality decreases (controlled for social security).

IMM4: Enrolment increases as social security increases (controlled for inequality). 